\title{
Do confident individuals generally work harder?
}

Pikulina, Elena ; Renneboog, Luc ; Tobler, Philippe N

\begin{abstract}
Predicting worker's effort is important in many different areas, but is often difficult. Using a laboratory experiment, we test the hypothesis that confidence, i.e. person-specific beliefs about her abilities, can be used as a generic proxy to predict effort provision. We measure confidence in the domain of financial knowledge in three different ways (self-assessed knowledge, probability-based confidence, and incentive-compatible confidence) and find a positive relation with the actual provision of effort in an unrelated domain. Additional analysis shows that the findings are independent of personal traits such as gender, age, and nationality.
\end{abstract}

DOI: https://doi.org/10.1016/j.mulfin.2018.01.004

Posted at the Zurich Open Repository and Archive, University of Zurich ZORA URL: https://doi.org/10.5167/uzh-168796

Journal Article

Accepted Version

Originally published at:

Pikulina, Elena; Renneboog, Luc; Tobler, Philippe N (2018). Do confident individuals generally work harder? Journal of Multinational Financial Management, 44:51-60.

DOI: https://doi.org/10.1016/j.mulfin.2018.01.004 


\title{
Do confident individuals generally work harder?*
}

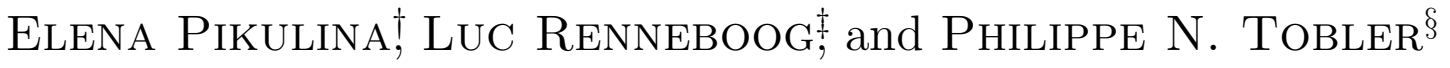

\begin{abstract}
Predicting worker's effort is important in many different areas, but is often difficult. Using a laboratory experiment, we test the hypothesis that confidence, i.e. person-specific beliefs about her abilities, can be used as a generic proxy to predict effort provision. We measure confidence in the domain of financial knowledge in three different ways (self-assessed knowledge, probability-based confidence, and incentive-compatible confidence) and find a positive relation with the actual provision of effort in an unrelated domain. Additional analysis shows that the findings are independent of personal traits such as gender, age, and nationality.
\end{abstract}

JEL Classification G11, J22

Keywords: Confidence, real-effort task, financial literacy, overconfidence

*Acknowledgments: We are grateful to Elena Asparouhova, Colin Camerer, Peter de Goeij, Alberto Manconi, Charles Noussair and Stefan Trautmann for useful comments and suggestions. We also acknowledge the contribution of the participants in the TIBER XI Conference, Florence Workshop on Behavioral and Experimental Economics, Experimental Finance Conference and seminar presentations at Caltech, UCSD, and Tilburg University. All remaining errors are our own. We gratefully acknowledge financial support from the CentER Fund for Experimental Research, the AXA foundation (Elena Pikulina), Inquire Europe (Luc Renneboog), and the Swiss National Science Foundation (Philippe Tobler).

${ }^{\dagger}$ Department of Finance, Sauder School of Business, University of British Columbia, 2053 Main Mall, Vancouver, BC V6T 1Z2, Canada. E-mail: elena.pikulina@sauder.ubc.ca.

${ }_{\ddagger}^{\ddagger}$ Department of Finance, Tilburg University, PO Box 90153, 5000 LE Tilburg, the Netherlands. E-mail: luc.renneboog@uvt.nl.

$\S$ Department of Economics, University of Zürich, Blumlisalpstrasse 10, 8006 Zürich, Switzerland. E-mail: phil.tobler@econ.uzh.ch. 


\title{
Do confident individuals generally work harder?
}

\begin{abstract}
Predicting worker's effort is important in many different areas, but is often difficult. Using a laboratory experiment, we test the hypothesis that confidence, i.e. person-specific beliefs about her abilities, can be used as a generic proxy to predict effort provision. We measure confidence in the domain of financial knowledge in three different ways (self-assessed knowledge, probability-based confidence, and incentive-compatible confidence) and find a positive relation with the actual provision of effort in an unrelated domain. Additional analysis shows that the findings are independent of personal traits such as gender, age, and nationality.
\end{abstract}

JEL Classification G11, J22

Keywords: Confidence, real-effort task, financial literacy, overconfidence 


\section{Introduction}

In many situations, principals need to predict how much effort agents will provide in the future, which is both useful and difficult. Accurately predicting effort is useful because it allows to make informed decisions. For example, when deciding to hire an assistant, a financial manager would benefit from being able to know ex ante how much effort and diligence the candidate will put into the assigned work. Predicting effort is difficult because the available information is often only weakly related to the domain in which effort will be exerted. When hiring a person fresh out of college, one can use average grades or grades in a specific subject, but they are likely to be noisy. Ideally, one would rely on a proxy that is easy to collect but nevertheless predictive of effort provision across different domains.

One candidate for such a proxy is confidence in one's abilities. To the best of our knowledge, a predictive relation of confidence in one domain on future effort provision in another domain has not been tested so far. For example, would an assistant's confidence in her financial knowledge also predict her effort and diligence in collecting and cleaning data required by the financial manager? To fill this gap, we use a laboratory experiment and investigate whether individuals' beliefs about their proficiency in one domain (in our case, financial knowledge) predict their effort in another domain (real-effort decoding task).

We measure individuals' confidence as their beliefs about their performance in a financial knowledge questionnaire ${ }^{1}$ and employ three different confidence measures: self-assessed number of questions answered correctly, average probability assigned by an individual that each of her answers is correct, and an incentive-compatible confidence measure. In psychology, confidence (or self-efficacy) is typically measured by means of directly asking people about their ability to perform a certain task (see Bandura (2006) for a detailed guide on self-efficacy scales). For the first two measures

\footnotetext{
${ }^{1}$ We use a questionnaire on financial knowledge rather than on general knowledge because the majority of our subjects are students with majors in Business or Economics.
} 
we follow this tradition and simply ask participants to state their beliefs about their performance in the financial knowledge questionnaire both in terms of the self-assessed number of correct answers and in terms of the probabilities that each of their answers is correct. By contrast, the economics literature generally emphasizes the importance of incentive-compatible measures. ${ }^{2}$ Our incentive-compatible confidence measure is in line with this tradition. By design of our experiment, the participants are monetarily worse-off by overstating or understating their financial knowledge and only receive a reward when they state unbiased beliefs about their proficiency.

In the main part of the experiment, the participants choose how much to work in a real-effort decoding task. We find that the participants with higher confidence in their financial knowledge work more intensively in our real-effort task. Moreover, both the self-assessed and the incentive-compatible measure of confidence are good predictors of effort provision.

This result is important because in many field situations, self-assessed confidence measures are easier and cheaper to collect than incentive-compatible ones.

The psychology literature has long emphasized confidence as the most important factor in forming high performance expectations and in the propensity to work hard to meet those expectations. Bandura (1982)). For example, Stajkovic and Luthans (1998) provide a meta-analysis of psychology and management studies, which investigate the relation between confidence in a certain domain (or specific self-efficacy, an individual's belief in his or her ability to succeed in a specific task) and effort-related performance in the same domain. They document a significant positive relationship between confidence and performance, with the relationship being stronger for simple tasks and tasks completed in the laboratory rather than in the field.

The recent economics literature investigates potential spillover effects of confi-

\footnotetext{
${ }^{2}$ For example, several papers on CEO overconfidence use personal managerial investments, specifically net purchases of their company stock, their stock-option holdings, and the timing of option exercises, as a proxy for managerial beliefs about their ability to create firm value (Huang and Kisgen (2013), Deshmukh et al. (2013), Schrand and Zechman (2012), Hirshleifer et al. (2012), Galasso and Simcoe (2011), Campbell et al. (2011), Billett and Qian (2008) and Malmendier and Tate (2005)).
} 
dence on effort provision (Gervais and Goldstein (2007), Falk et al. (2006), Bénabou and Tirole (2002)). For example, Bénabou and Tirole (2002) demonstrate that high confidence in one's abilities improves welfare for individuals with time-inconsistent preferences (e.g., hyperbolic discounting). In their model, decision makers in the present prefer a self-confident version of themselves in the future because higher confidence helps to resist the tendency to stop working too quickly. Falk et al. (2006) confirm this intuition and show that individuals with low confidence about their abilities abandon costly search much earlier than those with high confidence. Gervais and Goldstein (2007) study a model of a firm where the marginal productivity of individuals' efforts is amplified by other team members' efforts. In their model, the presence of an agent, who overestimates his marginal productivity and therefore exerts excessive effort, results in higher effort provision by his team members and a Pareto-improvement for the whole team. In other words, the presence of a confident agent helps to solve the free rider problem within a group. However, none of those studies has investigated a relationship between confidence and effort across domains.

We also investigate a relation between exaggerated confidence, i.e. overconfidence, and effort provision. We measure overconfidence in two different ways. Our first measure is overestimation (or optimism) which describes a situation where individuals believe their ability, achievements, level of control, or probability of success to be higher than they actually are. We define this measure as the difference between the participants' confidence in their performance and their actual performance. Our second overconfidence measure is the better-than-average measure (aka overplacement) that captures individuals' beliefs that they are better than the others (Moore and Healy (2008)). In our case, the better-than-average measure is a simple indicator variable that equals one if a participant believes that she answered more questions correctly than the average participant of our experiment, and zero otherwise. We find that overconfidence, both in terms of overestimation and better-than-average, positively predicts effort provision. 
These results help in interpreting the beneficial effects of confidence in social signalling, leadership, and risk taking. High confidence in one's ability in one domain can be used as a signal of future commitment and high effort provision in multiple domains. For example, being a successful leader requires a non-trivial effort in multiple unrelated domains (e.g. coordinating the workload, motivating team members to work at their full potential, creating a positive atmosphere, etc.). In line with this notion, Reuben et al. (2012) show that confident individuals are more likely to be selected as group leaders. Campbell et al. (2011) and Gervais et al. (2011) show that boards of directors prefer moderately overconfident CEOs to their diffident or highly overconfident peers because they are more motivated to take risky projects and are committed to exert more effort to resolve uncertainty about those projects. Furthermore, high confidence is important and beneficial in terms of pursuing new ideas (Hirshleifer et al. (2012), Galasso and Simcoe (2011), Simon and Houghton (2003)) and implementing entrepreneurial projects (Hayward et al. (2010), Hayward et al. (2006)) where both failure rates and uncertainty about future outcomes are high.

Both innovation and entrepreneurship require substantial and extended effort in various areas. Our results suggest that cross-domain effort exertion can be predicted from confidence in just one (and potentially unrelated) area.

The remainder of the paper proceeds as follows. Section 2 details the experimental design. The results are provided in Section 3. Section 4 concludes.

\section{Experimental Design}

The experiment consists of two parts. In the initial part, we assess subjects' selfconfidence in and actual knowledge of the financial domain. In the main part, subjects choose how much they want to work in a real-effort decoding task where their monetary reward depends only on their effort level. We begin with describing our effort task. 


\section{$2.1 \quad$ Real-Effort Task}

In the main part of the experiment subjects choose how much they want to work by selecting an effort level in a real-effort task. They have to decode a list of 30 long numbers and assign each number to one of several groups based on the last three digits of each number (see Figure 1). The number of groups in this menial task determines the intensity level: the list of 30 long numbers can be generated from 2 (the lowest intensity level of $20 \%$ or level 1), 4, 6, 8, or 10 (the highest intensity level of $100 \%$ or level 5) different groups. Subjects can choose their effort level by deciding on the intensity level and the corresponding number of groups from which to decode. For example (see Figure 1), if the long codes are generated from 4 different groups, their last three digits may come from intervals [300-399], [0-99], [600-699], and [700-799], where the exact interval choice is random and varies across subjects. Then, a subject would need to assign all the 30 long codes ending with numbers between 300 and 399 to group 1, the ones ending with numbers between 0 and 99 to group 2, etc.

The subjects' reward increases with their effort level from 1030 cents for the lowest effort level of $20 \%$ to 1450 cents for the highest effort level of $100 \%$ (see Panel A of Table 1 for the reward structure). To insure deliberate choices, subjects are trained to perform the task at different intensity levels before making the choices that actually matter for payment. Irrespective of their chosen effort level, all subjects have to assign all the 30 long numbers to their correct groups to receive the reward; in other words subjects cannot choose the highest effort level of $100 \%$, decode only a few numbers, and receive 1450 cents. To make sure that some of the subjects do not take forever to complete the task, we give them extra 50 cents for finishing the task within 150s. ${ }^{3}$ Before they start the task, subjects have to answer five comprehension questions about the task and the reward structure. If they give a wrong answer or if

${ }^{3}$ If anything, this design feature may make some subjects more conservative in their effort choices, i.e. they would have choosen higher effort levels if given unlimited time. However, any significant interference seems unlikely because 50 cents is less than $5 \%$ of the total reward even for the lowest effort level of $20 \%$. In fact, $67 \%$ of our subjects finish the task within the given time. 


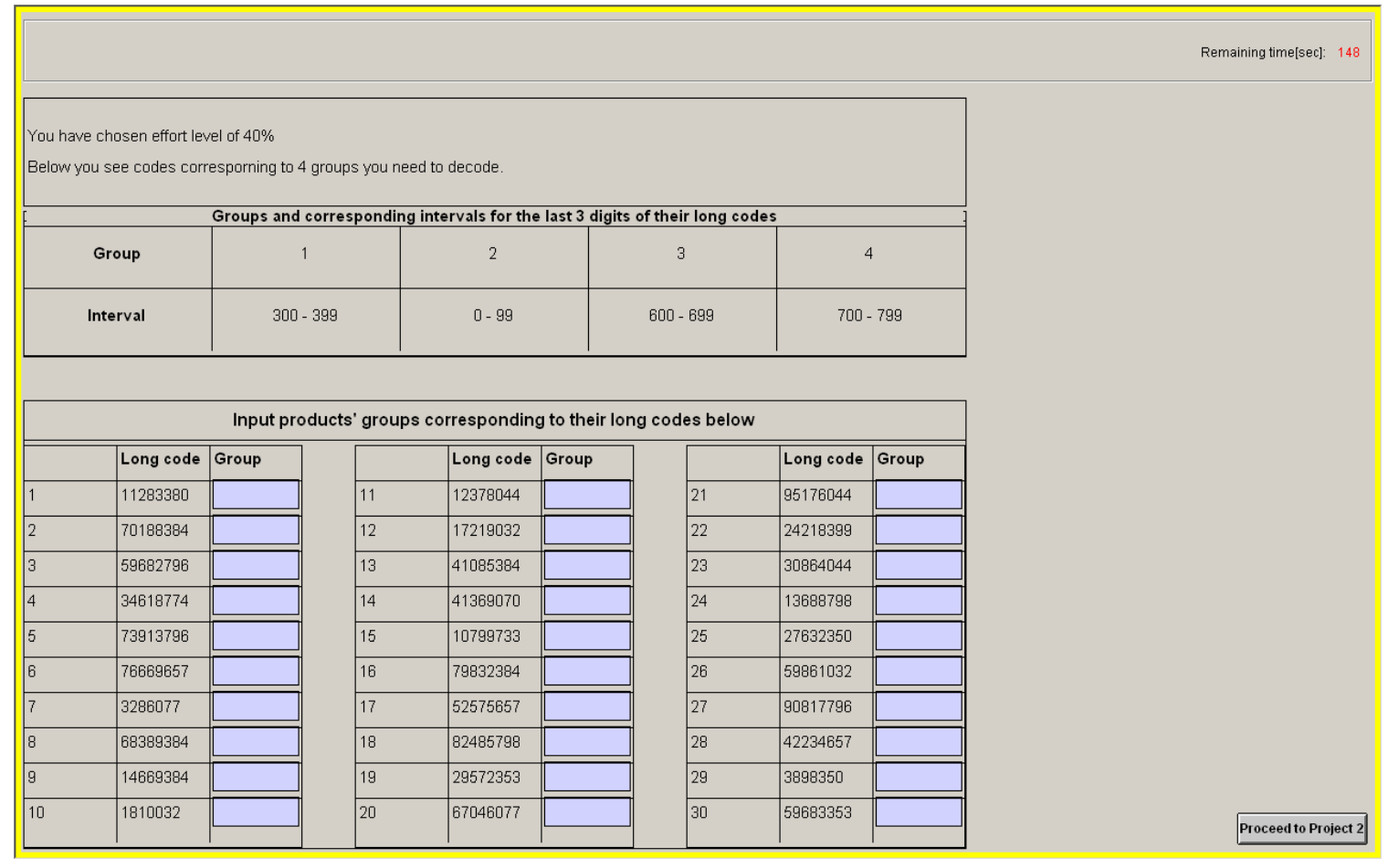

Figure 1: The Decoding Task

The screen shot presents a task for the effort level of $40 \%$, which corresponds to decoding 30 long numbers into 4 different groups, based on their last three digits. 
Table 1: Reward in the Real Effort and Incentivized Confidence Tasks

Panel A shows subjects' reward depending on their effort level in the main task. Panel B shows subjects' reward depending on their effort level and their skill level in the Incentivized Confidence task. To earn a reward, subjects must choose an effort level corresponding to their actual skill; otherwise they earn zero.

\begin{tabular}{lccccc}
\hline \multicolumn{2}{l}{ Panel A: Decoding Task } & & & & \\
\hline Effort level & $20 \%$ & $40 \%$ & $60 \%$ & $80 \%$ & $100 \%$ \\
Reward & 1030 & 1190 & 1350 & 1400 & 1450 \\
\hline
\end{tabular}

Panel B: Incentivized Confidence Task

\begin{tabular}{lccccc}
\hline Effort level & Skill 1 & Skill 2 & Skill 3 & Skill 4 & Skill 5 \\
\hline $20 \%$ & 1350 & 0 & 0 & 0 & 0 \\
$40 \%$ & 0 & 1350 & 0 & 0 & 0 \\
$60 \%$ & 0 & 0 & 1350 & 0 & 0 \\
$80 \%$ & 0 & 0 & 0 & 1350 & 0 \\
$100 \%$ & 0 & 0 & 0 & 0 & 1350 \\
\hline
\end{tabular}

they have questions, they receive additional explanations. The task starts when all the subjects answer all the questions correctly.

\subsection{Measures of Confidence}

Before performing the effort task (see above), subjects answer 20 financial knowledge questions ${ }^{4}$ by choosing between two alternative options (see Appendix A). For our main confidence measure, we ask subjects how many out of 20 questions they think they answered correctly. The exact question is "You were asked to answer 20 financial knowledge questions. For how many of these questions do you think you gave the correct answer? (State a number between 0 and 20.)" ${ }^{5}$ We also employ two additional confidence measures frequently used in the literature for robustness.

When answering the financial knowledge questionnaire, subjects also assign a

\footnotetext{
${ }^{4}$ Among others, our questions include those proposed by Van Rooij, Lusardi and Alessie (2011). We also include three questions from the cognitive reflection task by Frederick (2005).

${ }^{5}$ Subjects also answer the following question: "Other students were asked the same 20 financial knowledge questions. For an average student in this experiment how many answers do you think were correct? (State a number between 0 and 20)." We use this question to assess whether subjects believe that their performance is above average.
} 
Table 2: Number of Correct Answers and Skill Level

\begin{tabular}{l|ccccc}
\hline Number of correct answers & 11 or less & 12 or 13 & 14 or 15 & 16 or 17 & 18 or more \\
Skill level & 1 & 2 & 3 & 4 & 5 \\
\hline
\end{tabular}

probability to the chosen answer being correct. The probability is restricted to vary between $50 \%$ and $100 \%$ because there are only two alternative answers for each question. Our second confidence measure is the average of the probabilities that a subject has assigned to her answers.

\section{Incentivized Confidence Measure}

Our third confidence measure is elicited in an incentive-compatible manner. Once subjects finish the financial knowledge questionnaire, their knowledge or skill level in the financial domain is determined according to Table 2. Subjects do not know their performance in the questionnaire but they are shown Table 2 that enables them to form a belief about the number of correct answers they gave and about their corresponding skill level. We elicit subjects' beliefs about their skill level by asking them to choose an effort level in our real-effort task that corresponds to their presumed performance in the questionnaire (see Panel B of Table 1). If they choose the effort level that corresponds to their actual skill level, they obtain a reward of 1350 cents, otherwise they obtain nothing. For example, to receive a reward, a subject with skill level 1 should choose the $20 \%$ effort level, a subject with skill level 2 should choose the $40 \%$ effort level, etc. To guarantee that all subjects face identical incentives to assess their skill level correctly (they all receive the same reward for being right and they all bear the same costs for being wrong), all of them have to perform the decoding task at the same intensity level of $60 \%$, irrespective of the effort level they choose. By design, subjects are worse-off by overstating or understating their skill level in the financial domain and only receive a reward when they state unbiased beliefs about their proficiency. 


\section{Results}

Ninety students have participated in a 75-minutes long laboratory experiment, coded in Z-tree (Fischbacher (2007)) at the CentERLab of Tilburg University, the Netherlands. The average participant was 22 years old; there were 42 women; and 71 participants had majors in Business and Economics. The average earnings constituted about 13 Euros (or about $\$ 17$ at the time of the experiment).

\subsection{Financial Knowledge and Confidence}

Table 3 reports subjects' performance in the financial knowledge questionnaire, their confidence in the financial domain, and their effort in the decoding task for skill levels from 1 to 5 . On average, the subjects answer $66.5 \%$ of the financial knowledge questions correctly (as measured by the variable Financial Knowledge), which correspond to 13.3 out of 20 questions (see Table 3). However, they believe that they have answered 14.1 or $70.5 \%$ of questions correctly according to our main confidence measure. The mean difference between Self-Assessed \# of Correct Answers and Financial Knowledge is $4.0 \%$ and it is significantly different from zero at the $1 \%$ significance level. So, as one may have expected, the participants of our experiment are not only confident in their financial abilities, they are overconfident. ${ }^{6}$ The subjects' confidence in their financial knowledge is even higher according to our probability-based confidence measure. According to the Average Probability measure, the subjects believe that on average they have answered 16.9 or $84.5 \%$ questions correctly. The mean difference between Average Probability and Financial Knowledge is $18.0 \%$ and it is significantly different from zero at the $1 \%$ significance level.

One may argue that giving a higher score for the first two measures is free and simply makes subjects feel better about themselves. However, providing strong incentives

${ }^{6}$ For example, in their summary of the micro foundations of behavioural finance, De Bondt and Thaler (1994) state that "perhaps the most robust finding in the psychology of judgment is that people are overconfident" (p. 389). 
Table 3: Financial Knowledge, Confidence, and Effort

Panel A presents the summary statistics for the subjects' performance in the financial knowledge questionnaire, their confidence, and effort by the subjects' skill level. Panel B presents the correlations between the above mentioned variables. * stands for $p<0.10$, ** for $p<0.05$, and *** for $p<0.01$.

\begin{tabular}{|c|c|c|c|c|c|c|c|}
\hline \multicolumn{8}{|c|}{ Panel A. Summary statistics by skill level } \\
\hline Skill Level & All & 1 & 2 & 3 & 4 & 5 & $4 \& 5-1$ \\
\hline \# of Subjects & 90 & 21 & 26 & 23 & 16 & 4 & - \\
\hline Financial Knowledge & 66.5 & 47.6 & 62.3 & 73.0 & 82.5 & 91.3 & $36.6^{* *}$ \\
\hline $\begin{array}{l}\text { Self-Assessed \# } \\
\text { of Correct Answers }\end{array}$ & 70.5 & 66.7 & 66.5 & 71.7 & 76.6 & 85.0 & $11.6^{* *}$ \\
\hline Average Probability & 84.5 & 84.5 & 81.8 & 84.4 & 88.1 & 89.1 & 3.7 \\
\hline Self-Assessed Skill & 3.01 & 2.86 & 2.54 & 3.17 & 3.50 & 4.00 & 0.7 \\
\hline Effort & 3.84 & 3.76 & 3.88 & 3.83 & 3.88 & 4.00 & 0.14 \\
\hline \multicolumn{8}{|c|}{ Panel B. Correlation Matrix } \\
\hline Variable & & $(1)$ & $(2)$ & $(3)$ & $(4)$ & $(5)$ & (6) \\
\hline (1) Financial Knowledge & & - & & & & & \\
\hline $\begin{array}{l}\text { (2) Self-Assessed \# } \\
\text { of Correct Answers }\end{array}$ & & $0.43^{* * *}$ & - & & & & \\
\hline (3) Average Probability & & $0.18^{*}$ & $0.57^{* * *}$ & - & & & \\
\hline (4) Self-Assessed Skill & & $0.30^{* * *}$ & $0.70^{* * *}$ & $0.47^{* * *}$ & - & & \\
\hline (5) Skill & & $0.96^{* * *}$ & $0.41^{* * *}$ & $0.19^{*}$ & $0.30^{* * *}$ & - & \\
\hline (6) Effort & & 0.07 & $0.27^{* * *}$ & $0.24^{* *}$ & $0.20^{*}$ & 0.04 & - \\
\hline
\end{tabular}


to correctly assess their performance does not remove the subjects' overconfidence as shown by our third confidence measure, Self-Assessed Skill. The subjects believe that their average skill level is 3.01 (out of 5.00), which is significantly higher than their actual skill level of $2.51(t=3.56, p<0.001)$. Note that the subjects receive zero monetary reward if they are too optimistic or too pessimistic about their skill level. Thus, even though the subjects are provided with substantial monetary incentives to assess their performance objectively, they remain over-optimistic about their financial knowledge.

\subsection{Effort Provision}

According to Table 3, the subjects' average effort choice is equal to 3.84 (intensity levels ranging from 1 to 5$)$ and it is significantly below $5(t=11.16, p<0.001)$, indicating that subjective effort cost is non-trivial in our experimental task. It is worth noting that the subjects' effort choice is not affected by their actual knowledge in the financial domain: the effort level does not change significantly across different skill levels: the average effort levels for skill level 1 and skill level 5 are not statistically different from each other. Moreover, Financial Knowledge and Skill are not correlated with the Effort variable (see Panel B, Table 3). In other words, the subjects' effort choice is not affected by their actual knowledge in the financial domain.

Next, we address the question whether effort provision can be predicted with confidence measures from a different domain. Most importantly, the Effort variable is positively correlated with all the three confidence measures, Self-Assessed \# of Correct Answers, Average Probability, and Self-Assessed Skill, even though the realeffort task is completely unrelated to financial knowledge. Thus, subjects' confidence or their beliefs about their financial skills rather than their actual financial skills are predictive of effort provision.

To confirm further that confidence increases effort provision, we compare effort choices between the subjects with low and high confidence levels (within bottom 


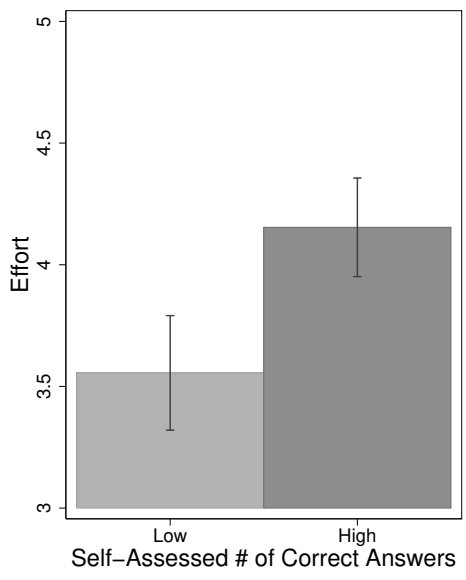

$(2 \mathrm{a})$

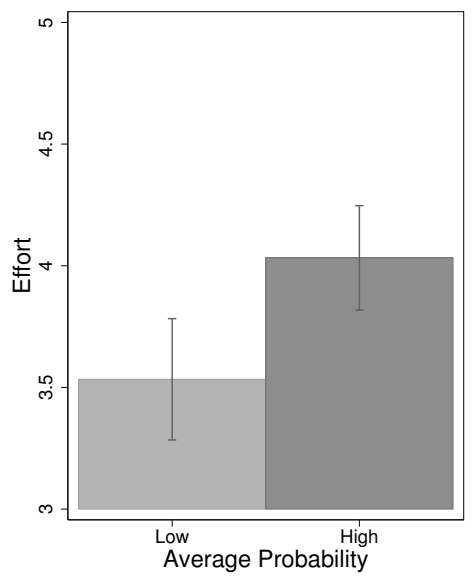

$(2 \mathrm{~b})$

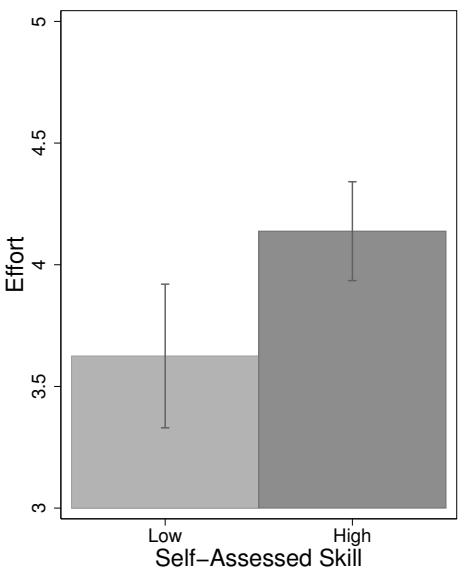

$(2 \mathrm{c})$

Figure 2

\section{Effort and Confidence}

The figure presents the average effort choice for the subjects with low and high confidence levels; vertical bars depict average effort levels and vertical lines represent $10 \%$ standard errors.

and top terciles). According to Figure 2, the subjects with high confidence choose to work more than those with low confidence. The difference in effort levels is significant within the $10 \%$ significance level for all three confidence measures: for the Self-Assessed \# of Correct Answers measure the $t$-statistic is equal to 2.40, with a $p$-value of 0.02 ; for Average Probability the $t$-statistic is $1.99(p=0.05)$; for SelfAssessed Skill the $t$-statistic is $1.93(p=0.06)$.

\subsection{Multivariate Analysis}

We further characterize the relationship between confidence and effort choice in a multivariate setting. The dependent variable is Effort and the explanatory variables are the three different confidence measures, the subjects' actual skill level, and their personal characteristics. The results are reported in Table 4.

In model (1), we use Self-Assessed \# of Correct Answers as the only explanatory 
variable to predict the subjects' effort choice in our real-effort task. We find that the subjects with higher confidence in their financial knowledge work harder in the unrelated domain of decoding. In model (2) we add the actual subjects' skill level and their personal characteristics as explanatory variables. ${ }^{7}$ We control for the following subject characteristics: gender (a dummy variable equal to 1 for female subjects; 0 otherwise), age (in years), nationality ${ }^{8}$ (a dummy variable for subjects who indicate that they grew up in the People's Republic of China; 0 otherwise), and study major (a dummy variable equal to 1 for subjects with majors in Business or Economics; 0 otherwise). None of the additional controls ${ }^{9}$ seem to explain the subjective effort choice in a persistent and significant manner. Most importantly, the coefficient for the confidence measure remains unchanged.

In models (3) and (4), we use Average Probability and Self-Assessed Skill as alternative measures of the subjects' confidence in their financial knowledge. According to both models, the two measures of confidence are positively related to the subjects' effort choice; also both measures are significant in the regression models with (Table 4) and without (not shown) controls. Thus, irrespective of the specific measure used, confidence in financial knowledge predicts effort provision in a task that is unrelated to this knowledge, whereas the actual financial knowledge does not.

\footnotetext{
${ }^{7}$ Despite a positive and significant correlation between the variables Self-Assessed \# of Correct Answers and Skill, there is no multicollinearity problem in model (2); the average VIF is only 1.17.

${ }^{8}$ Several studies point out that in comparison with many Western cultures, the Chinese culture emphasizes the importance of effort and persistence in achieving goals (Leung (2010), Chen and Uttal (1988)). For example, according to Chen and Uttal (1988), while "innate ability may determine the rate at which one acquires new knowledge, the ultimate level of achievement is attained through effort."

${ }^{9}$ As further robustness tests, we add some more explanatory variables in the multivariate regression. We measure subjects' risk aversion via the Holt and Laury (2002) task and cognitive reflection score (CRS) via questions by Frederick (2005). Both risk aversion and CRS variables are insignificant and do not affect our main result.
} 


\section{Table 4: Impact of Confidence on Effort Choice}

The table reports the results of OLS regression models for the subjects' effort level choice. The dependent variable is Effort, the subjects' effort level, exerted in the experimental real-effort task. The explanatory variables are the three different measures of confidence, subjects' actual skill level, and subjects' personal characteristics.

* stands for $p<0.10,{ }^{* *}$ for $p<0.05$, and $* * *$ for $p<0.01$. Standard errors are in parentheses.

\begin{tabular}{|c|c|c|c|c|}
\hline \multirow{2}{*}{$\begin{array}{l}\text { Dependent variable } \\
\text { Model }\end{array}$} & \multicolumn{4}{|c|}{ Effort } \\
\hline & (1) & $(2)$ & (3) & (4) \\
\hline $\begin{array}{l}\text { Self-Assessed \# } \\
\text { of Correct Answers }\end{array}$ & $\begin{array}{l}0.024^{* * *} \\
(0.009)\end{array}$ & $\begin{array}{l}0.026^{* *} \\
(0.010)\end{array}$ & & \\
\hline Average Probability & & & $\begin{array}{r}0.025^{*} \\
(0.014)\end{array}$ & \\
\hline Self-Assessed Skill & & & & $\begin{array}{r}0.172^{*} \\
(0.100)\end{array}$ \\
\hline Skill & & $\begin{array}{l}-0.050 \\
(0.098)\end{array}$ & $\begin{array}{c}0.020 \\
(0.093)\end{array}$ & $\begin{array}{l}-0.004 \\
(0.096)\end{array}$ \\
\hline Female & & $\begin{array}{l}-0.136 \\
(0.209)\end{array}$ & $\begin{array}{l}-0.159 \\
(0.213)\end{array}$ & $\begin{array}{l}-0.206 \\
(0.210)\end{array}$ \\
\hline Age & & $\begin{array}{l}-0.005 \\
(0.034)\end{array}$ & $\begin{array}{l}-0.009 \\
(0.035)\end{array}$ & $\begin{array}{l}-0.001 \\
(0.035)\end{array}$ \\
\hline Chinese & & $\begin{array}{c}0.369 \\
(0.240)\end{array}$ & $\begin{array}{c}0.307 \\
(0.251)\end{array}$ & $\begin{array}{c}0.406 \\
(0.244)\end{array}$ \\
\hline $\begin{array}{l}\text { Major in Business } \\
\text { or Economics }\end{array}$ & & $\begin{array}{l}-0.332 \\
(0.256)\end{array}$ & $\begin{array}{l}-0.315 \\
(0.261)\end{array}$ & $\begin{array}{l}-0.284 \\
(0.260)\end{array}$ \\
\hline Constant & $\begin{array}{l}2.141^{* * *} \\
(0.645)\end{array}$ & $\begin{array}{l}2.475^{* * *} \\
(0.932)\end{array}$ & $\begin{array}{r}2.099^{*} \\
(1.225)\end{array}$ & $\begin{array}{l}3.583^{* * *} \\
(0.793)\end{array}$ \\
\hline Observations & 90 & 90 & 90 & 90 \\
\hline Adj. $R^{2}$ & 0.065 & 0.065 & 0.031 & 0.027 \\
\hline
\end{tabular}




\subsection{Overconfidence and Effort}

The previous literature shows that too much confidence (i.e. overconfidence) can be detrimental for individual decision making. ${ }^{10}$ In our case, there may be limits to the beneficial effects of confidence on real effort provision. We therefore investigate whether subjects' effort choice is affected by their overconfidence. Following the standard definition (see for example, Moore and Healy (2008)), we capture overconfidence as the difference between the subjects' beliefs about their financial knowledge (i.e. confidence) and their actual knowledge. ${ }^{11}$ In particular, we measure overconfidence in four different ways. OC1 is the difference between the number of correct answers a subject believes she gave (Self-Assessed \# of Correct Answers) and the actual number of correct answers, in percentage points. OC2 is the difference between the probability-based confidence measure (Average Probability) and the actual number of correct answers, in percentage points. OC3 is the difference between the subjects' incentive-compatible skill level (Self-Assessed Skill) and their actual skill level. Finally, Better-than-Average (BtA) is a dummy variable, equal to 1 for those subjects who believe that their performance in the financial knowledge questionnaire is higher than the average performance of others; 0 otherwise. We regress the subjects' effort choice on different overconfidence measures, their actual skill level, and their personal characteristics. The results are reported in Table 5 .

We find that three out of four overconfidence measures are positively and significantly related to the subjects' effort choice. OC1 and BtA have the highest explanatory power in terms of adjusted R-squared (see models (1) and (4)). So, not only the degree to which subjects overestimate their ability relative to their actual ability but also relative to the ability of others can positively affect their propensity to exert

\footnotetext{
${ }^{10}$ The detrimental effects of overconfidence range from value-destroying decisions of CEOs (Deshmukh et al. (2013), Schrand and Zechman (2012), Malmendier and Tate (2008), Hayward and Hambrick (1997)) to poor decision quality of VCs (Zacharakis and Shepherd (2001)) and to poor investor performance (Grinblatt and Keloharju (2009), Barber and Odean (2001)).

${ }^{11}$ Note that this definition allows also for underconfidence when subjects hold inferior beliefs about their knowledge in comparison to their actual knowledge.
} 


\section{Table 5: Impact of Overconfidence on Effort Choice}

The table reports the results of OLS regression models for the subjects' effort level choice. The dependent variable is Effort and the main explanatory variables are four different measures of overconfidence. $O C 1$ is the difference between Self-Assessed \# of Correct Answers and the actual number of correct answers, in percentage points. OC2 is the difference between Average Probability and the actual number of correct answers, in percentage points. OC3 is the difference between Self-Assessed Skill and Skill, the actual skill level. BtA is a dummy variable, equal 1 for those subjects who believe that their performance in the financial knowledge questionnaire is higher than the performance of others; 0 otherwise. ${ }^{*}$ stands for $p<0.10,{ }^{* *}$ for $p<0.05$, and ${ }^{* * *}$ for $p<0.01$. Standard errors are in parentheses.

\begin{tabular}{lcccc}
\hline Variable & $(1)$ & $(2)$ & $(3)$ & $(4)$ \\
\hline OC1 & $0.021^{* *}$ & & & \\
OC2 & $(0.010)$ & & & \\
OC3 & & 0.014 & & \\
& & $(0.012)$ & $0.172^{*}$ & \\
BtA & & $(0.100)$ & $0.495^{* *}$ \\
& & & $(0.238)$ \\
Skill & & & 0.011 \\
& & & & $(0.093)$ \\
Female & 0.198 & 0.181 & 0.169 & -0.122 \\
& $(0.121)$ & $(0.158)$ & $(0.120)$ & $(0.215)$ \\
Age & -0.191 & -0.220 & -0.206 & -0.008 \\
& $(0.209)$ & $(0.212)$ & $(0.210)$ & $(0.035)$ \\
Chinese & -0.002 & -0.002 & -0.001 & 0.341 \\
& $(0.034)$ & $(0.035)$ & $(0.035)$ & $(0.245)$ \\
Major in Business & 0.373 & 0.353 & 0.406 & -0.356 \\
or Economics & $(0.244)$ & $(0.253)$ & $(0.244)$ & $(0.262)$ \\
& -0.285 & -0.269 & -0.284 & $3.922^{* * *}$ \\
Constant & $(0.258)$ & $(0.262)$ & $(0.260)$ & $(0.777)$ \\
& & & & \\
Observations & $3.528^{* * *}$ & $3.400^{* * *}$ & $3.583^{* * *}$ & 0.042 \\
Adj. R ${ }^{2}$ & $(0.789)$ & $(0.874)$ & $(0.793)$ & \\
\hline
\end{tabular}


effort in our real-effort task.

\section{Conclusion}

Our study extends the notion that self-confidence is a valuable individual trait. Our findings suggest that high confidence in one domain (financial knowledge) is predictive of real-effort provision in a completely different domain (a laborious task, the piece-meal decoding of a list of numbers). Thus, subjects with high confidence in their financial proficiency tend to work more than their peers with low confidence in an unrelated real-effort task. In our experiment, we employ three different measures of confidence: self-assessed number of correct answers in the financial knowledge questionnaire, the average probability that given answers are correct, and an incentive-compatible confidence measure. Each of the three measures is positively related to the subjects' real effort. Our results are robust when controlling for a set of subject characteristics, including gender, age, nationality, study major, risk-aversion, and cognitive reflection score. In conclusion, the present study may provide leads for investigating whether simple confidence measures could be used as predictors of real-effort provision in different settings. 


\section{References}

Bandura, Albert (1982), 'Self-efficacy mechanism in human agency', American Psychologist 37(2), 122.

Bandura, Albert (2006), 'Guide for constructing self-efficacy scales', Self-Efficacy Beliefs of Adolescents 5(307-337).

Barber, Brad M and Terrance Odean (2001), 'Boys will be boys: Gender, overconfidence, and common stock investment', The Quarterly Journal of Economics pp. 261-292.

Bénabou, Roland and Jean Tirole (2002), 'Self-confidence and personal motivation', The Quarterly Journal of Economics pp. 871-915.

Billett, Matthew T and Yiming Qian (2008), 'Are overconfident CEOs born or made? Evidence of self-attribution bias from frequent acquirers', Management Science 54(6), 10371051.

Campbell, T Colin, Michael Gallmeyer, Shane A Johnson, Jessica Rutherford and Brooke W Stanley (2011), 'CEO optimism and forced turnover', Journal of Financial Economics 101(3), 695-712.

Chen, Chuansheng and David H Uttal (1988), 'Cultural values, parents' beliefs, and children's achievement in the United States and China', Human Development 31(6), 351-358.

De Bondt, Werner FM and Richard H Thaler (1994), Financial decision-making in markets and firms: A behavioral perspective. National Bureau of Economic Research.

Deshmukh, Sanjay, Anand M Goel and Keith M Howe (2013), 'CEO overconfidence and dividend policy', Journal of Financial Intermediation 22(3), 440-463.

Falk, Armin, David Huffman and Uwe Sunde (2006), 'Self-confidence and search', IZA Discussion Paper .

Fischbacher, Urs (2007), 'z-tree: Zurich toolbox for ready-made economic experiments', Experimental Economics 10(2), 171-178. 
Frederick, Shane (2005), 'Cognitive reflection and decision making', Journal of Economic Perspectives pp. 25-42.

Galasso, Alberto and Timothy S Simcoe (2011), 'CEO overconfidence and innovation', Management Science 57(8), 1469-1484.

Gervais, Simon and Itay Goldstein (2007), 'The positive effects of biased self-perceptions in firms', Review of Finance 11(3), 453-496.

Gervais, Simon, JB Heaton and Terrance Odean (2011), 'Overconfidence, compensation contracts, and capital budgeting', The Journal of Finance 66(5), 1735-1777.

Grinblatt, Mark and Matti Keloharju (2009), 'Sensation seeking, overconfidence, and trading activity', The Journal of Finance 64(2), 549-578.

Hayward, Mathew LA, Dean A Shepherd and Dale Griffin (2006), 'A hubris theory of entrepreneurship', Management Science 52(2), 160-172.

Hayward, Mathew LA and Donald C Hambrick (1997), 'Explaining the premiums paid for large acquisitions: Evidence of CEO hubris', Administrative Science Quarterly pp. 103127.

Hayward, Mathew LA, William R Forster, Saras D Sarasvathy and Barbara L Fredrickson (2010), 'Beyond hubris: How highly confident entrepreneurs rebound to venture again', Journal of Business Venturing 25(6), 569-578.

Hirshleifer, David, Angie Low and Siew Hong Teoh (2012), 'Are overconfident CEOs better innovators?', The Journal of Finance 67(4), 1457-1498.

Holt, Charles A and Susan K Laury (2002), 'Risk aversion and incentive effects', The American Economic Review 92(5), 1644-1655.

Huang, Jiekun and Darren J Kisgen (2013), 'Gender and corporate finance: Are male executives overconfident relative to female executives?', Journal of Financial Economics 108(3), 822-839. 
Leung, Kwok (2010), 'Beliefs in Chinese culture', The Oxford Handbook of Chinese Psychology pp. 221-240.

Malmendier, Ulrike and Geoffrey Tate (2005), 'CEO overconfidence and corporate investment', The Journal of Finance 60(6), 2661-2700.

Malmendier, Ulrike and Geoffrey Tate (2008), 'Who makes acquisitions? CEO overconfidence and the market's reaction', Journal of Financial Economics 89(1), 20-43.

Moore, Don A and Paul J Healy (2008), 'The trouble with overconfidence.', Psychological Review 115(2), 502.

Reuben, Ernesto, Pedro Rey-Biel, Paola Sapienza and Luigi Zingales (2012), 'The emergence of male leadership in competitive environments', Journal of Economic Behavior \& Organization 83(1), 111-117.

Schrand, Catherine M and Sarah LC Zechman (2012), 'Executive overconfidence and the slippery slope to financial misreporting', Journal of Accounting and Economics 53(1), 311-329.

Simon, Mark and Susan M Houghton (2003), 'The relationship between overconfidence and the introduction of risky products: Evidence from a field study', Academy of Management Journal 46(2), 139-149.

Stajkovic, Alexander D and Fred Luthans (1998), 'Self-efficacy and work-related performance: A meta-analysis.', Psychological Bulletin 124(2), 240.

Van Rooij, Maarten, Annamaria Lusardi and Rob Alessie (2011), 'Financial literacy and stock market participation', Journal of Financial Economics 101(2), 449-472.

Zacharakis, Andrew L and Dean A Shepherd (2001), 'The nature of information and overconfidence on venture capitalists' decision making', Journal of Business Venturing 16(4), 311-332. 


\section{Appendix A Financial Knowledge Questionnaire}

The appendix presents twenty financial knowledge questions with two alternative answers each; the correct answer is in bold.

1. Inflation may create problems in many ways. Which group would have the greatest problem during periods of high inflation that last several years? (i) Older people living on fixed retirement income; (ii) Young working couples with children and a mortgage.

2. If interest rates rise, what will typically happen to bond prices? (i) Fall; (ii) Rise.

3. Buying a single company's stock usually provides (i) a safer return than a stock mutual fund; (ii) a riskier return than a stock mutual fund.

4. Justin just found a job with a take-home pay of $€ 2,000$ per month. He must pay $€ 800$ for rent and $€ 200$ for groceries each month. He also spends $€ 200$ per month on transportation. If he budgets $€ 100$ each month for clothing, $€ 150$ for restaurants and $€ 250$ for everything else, how long will it take him to accumulate savings of $€ 900$. (Assume no interest rate payment on savings). (i) 3 months; (ii) 5 months.

5. A young person with $\$ 100,000$ to invest should hold riskier financial investment than an older person with $\$ 100,000$ to invest. (i) True; (ii) False.

6. In investor wants to buy a house but does not have sufficient funds. He invests in a risky project and his investment (including the returns) doubles in size every quarter. If it takes 48 quarters to reach the necessary funds to purchase the house, how many quarters would it take to have sufficient funds to purchase half of the house? (i) 24 quarters; (ii) 47 quarters.

7. Scott and Eric are young men. Each has a good credit history. They work at the same company and make approximately the same salary. Scott has borrowed $€ 6,000$ to take a foreign vacation. Eric has borrowed $€ 6,000$ to buy a car. Who is likely to pay the lowest finance charge? (i) Eric will pay less because the car is collateral for the loan; (ii) They will both pay the same because consumer credits have the same interest rate.

8. Elena started her pension program at age 20 and put in $€ 2,000$ each year for 15 years. Rebecca started her pension program at age 35 and put in $€ 2,000$ each year for 30 years. If they both get $6 \%$ per year on their investments, who will have more money at age 65? (i) Elena; (ii) Rebecca.

9. Employees should have the majority of their retirement funds in their current employers stock. (i) True; (ii) False. 
10. If it takes 5 machines 5 minutes to make 5 widgets, how long would it take 100 machines to make 100 widgets? (i) 5 minutes; (ii) 100 minutes.

11. It is possible for investors to be diversified even if they invest all their money in one mutual fund. (i) True; (ii) False.

12. You should rather have $\$ 5,000$ or a Euro cent doubled every day for a month? (i) True; (ii) False.

13. Yolanda has three credit cards and she owes $€ 500$ on each of them. The interest rates are $7 \%$ for card A, $9 \%$ for card B and $8 \%$ for card C. If Yolanda has $€ 1,000$ to pay some of her debt, which cards should she pay if she wants to minimize future interest payments? (i) €500 to card B and $€ 500$ to card C; (ii) $€ 333$ to card A and $€ 334$ to card B and $€ 333$ to card C.

14. How do income taxes affect the income that people have to spend? (i) They decrease spendable income in deflationary times and increase spendable income in inflationary times. (ii) They decrease the amount of goods and services that can be purchased.

15. A bat and a ball cost 1.10 Euro in total. The bat cost 1 Euro more than the ball. How much does the ball cost? (i) 0.10 Euro; (ii) 0.05 Euro.

16. At takeovers, the bidding firm usually pays a large premium to the target firm. Therefore, upon announcement, the target firm's share price increases substantially as it anticipates the premium to be paid in the takeover. Hence, if you own shares of a target firm (before the announcement), you will very likely make a large profit if you sell them after the announcement. (i) True; (ii) False.

17. You invest $€ 1000$ in a project and the discount factor is $10 \%$. The return is expected to be $€ 1100$ in year 1 and $€ 1200$ in year 2 (when the project ends). The net present value is approximately: (i) €1000; (ii) €1300.

18. If you have to sell one of your stocks, you should sell one which has gone up in price rather than one which has gone down. (i) True; (ii) False.

19. To do well in the stock market, you should buy and sell your stocks often. (i)True; (ii) False.

20. The cost of capital of the average listed firm consists is about (i) $\mathbf{1 0 \%}$; (ii) $20 \%$. 